\title{
Prospecção Tecnológica como uma Ferramenta para Criação de uma Luminária Pública Multifuncional Inteligente
} Technological Prospecting of Intelligent Multifunctional Street Light

\author{
Carlos Barros Rodrigues ${ }^{1}$ \\ Gabriela Silva Cerqueira ${ }^{1}$ \\ Cristine Elizabeth Alvarenga Carneiro ${ }^{1}$ \\ ${ }^{1}$ Universidade Federal do Oeste da Bahia, Barreiras, BA, Brasil
}

\begin{abstract}
Resumo
A iluminação pública desempenha uma importante função na sociedade, principalmente quanto à locomoção $e$ à segurança das pessoas, e está inserida em um mercado inovador, tendo recentemente incorporado novas funcionalidades. Este trabalho pretende verificar o avanço tecnológico da iluminação pública, e das várias tecnologias a ela incorporadas, de forma individual e associada. Para a elaboração deste artigo, foram definidas estratégias de pesquisa nos bancos de dados de patentes nacionais do INPI e internacionais, como o Espacenet $e$ o Orbit Intelligence, sendo quantificadas e analisadas por meio de tabelas e gráficos que apresentassem aspectos relevantes do mercado. Para os resultados que agregavam mais tecnologias, se assemelhando ao produto que será desenvolvido, a Luminária Pública Multifuncional Inteligente, foi necessário realizar uma análise qualitativa detalhada de cada patente, ampliada para o resumo, as reinvindicações e os desenhos. Os resultados mostraram que essas tecnologias despontaram na última década, com forte incremento, estando concentradas no mercado asiático liderados pela China, seguido pela Coreia do Sul.
\end{abstract}

Palavras-chave: Luminária Pública. LED. Solar.

\begin{abstract}
Public lighting plays an important role in society, especially because of people's mobility and safety. This technology is part an innovative market having recently incorporated new embedded features. This work aim verifies the technological advancement of public lighting, and others technologies incorporated, individually or associated to it. In technological prospecting search strategies in the INPI's, National Patent Databases and in international ones, such as Espacenet and Orbit Intelligence were used, being quantified and analyzed through tables and graphs, which presented relevant aspects of the market. It was necessary to make a detailed analysis of each research patent, rate the summary, claims and drawings to results that added more technologies similar to the product will be developed, the Intelligent Multifunctional Public Lighting. The results showed that these technologies emerged in the last decade, with a strong increase, being concentrated in the Asian market led by China, followed by South Korea.
\end{abstract}

Keywords: Street Light. LED. Solar.

Área Tecnológica: Redes de Comunicação sem Fio. Cidades Inteligentes. Internet das Coisas. 


\section{Introdução}

A iluminação pública desempenha fundamental papel para os moradores de um local e expressa a qualidade de um município. Com uma boa iluminação pública ações criminosas em ruas podem ser evitadas, assim como acidentes de trânsito, ou seja, uma iluminação precária traz prejuízos não apenas para a comunidade como também para os cofres públicos devido aos elevados gastos em função da utilização de mais serviços, por exemplo, de hospitais. A iluminação pública tem também função artística, embeleza as áreas urbanas, e, ainda, ajuda na construção da identidade local, valorizando a arquitetura e o patrimônio histórico das cidades (ELETROBRÁS, 2019). Uma das finalidades do serviço de iluminação pública, conforme a prevê a NBR 5101 (ABNT, 2018), é a de fornecer visibilidade ao trânsito, aos logradouros públicos e aos pedestres nas calçadas, nos parques e nas praças no período noturno. Com uma boa gestão, o serviço de iluminação pública garante qualidade de vida, permite aos cidadãos usufruir com segurança do espaço urbano durante a noite, especialmente quanto à mobilidade (CLEMENTE, 2018).

A Resolução n. 414/2010 da Agência Nacional de Energia Elétrica (ANEEL), em seu artigo 218, transfere integralmente todos os ativos de iluminação pública, das concessionárias de energia elétrica para o poder público municipal, e essa resolução também dispõe sobre diversos tópicos da iluminação pública, incluindo escurecimentos diurnos ocasionais, logradouros públicos e aqueles que necessitem de iluminação permanente no período diurno (ANEEL, 2010).

Existe um Programa Nacional de Conservação de Energia Elétrica (PROCEL) criado em 1985 pelo governo federal e executado e gerido pelas Centrais Elétricas Brasileira S.A. (ELETROBRÁS), por meio do Comitê Gestor de Eficiência Energética (CGEE) e do Grupo Coordenador de Conservação de Energia Elétrica (GCCE), com ações voltadas para o aumento da eficiência dos bens e serviços, a disseminação de conhecimento sobre o uso eficiente da energia e para a adoção de hábitos de consumo mais conscientes (ANNEL, 2020). Dessa forma, o programa ajuda a combater o desperdício e contribui para postergar investimentos no setor elétrico, reduzir emissões de gases de efeito estufa e mitigar impactos ambientais, colaborando para um mundo mais sustentável. Apenas em 2017, o PROCEL contemplou diversos projetos inovadores de iluminação pública e alcançou uma economia de aproximadamente 21,2 bilhões de quilowatts-hora (kWh) (ELETROBRÁS, 2019).

A promoção e o incentivo à inovação de produto ou processos envolvem a participação do governo, por meio de estímulos fiscais a empresas, de maneira a desenvolver competitividade e aumentar a produtividade delas, além de incentivar a proteção da propriedade intelectual gerada por meio do depósito de patentes. Contudo, as empresas devem realizar alguns esforços dentro do processo inovativo, que dependerá tanto de aspectos objetivos quanto de razões aleatórias e estruturais, como o próprio momento concreto vivenciado pela economia (CLEMENTE; SILVA, 2018).

Os melhores indicadores a serem utilizados para mensurar a inovação nos países são os números de depósitos de patentes, visto que esses depósitos possuem forte equivalência ao número de invenções. Os países asiáticos se destacam quanto a esse indicador, liderados pela China com forte incentivo governamental e com uma política voltada para a integração digital como parte de uma estratégia de desenvolvimento econômico, em face das potencialidades que surgem e pela amplitude do mercado a ser alcançado. A conectividade digital, além de alterar 
o funcionamento dos mercados, contribuiu para a aceleração do processo de desenvolvimento global (BARRERA, 2017).

A Imagem 1 traz fotos da moderna iluminação pública LED - Diodo Emissor de Luz, nas avenidas centrais da cidade de Barreiras/BA, que foi inaugurada pela Prefeitura Municipal em maio de 2021. A substituição do antigo sistema de iluminação com postes de concreto e lâmpadas de vapor metálico de $400 \mathrm{~W}$ por postes metálicos com dois braços e com luminárias de LED de $150 \mathrm{~W}$ e cabeamento subterrâneo segue uma tendência das grandes cidades, que já utilizam e tiveram uma economia em torno de 50 a 70\%, visto que a tecnologia LED é mais eficiente e com maior vida útil, reduzindo os gastos de consumo de energia e manutenção $e$ proporcionando uma mudança significativa no visual (PMB, 2021).

Imagem 1 - Fotos de iluminação pública em Barreiras/BA e foto de uma luminária LED
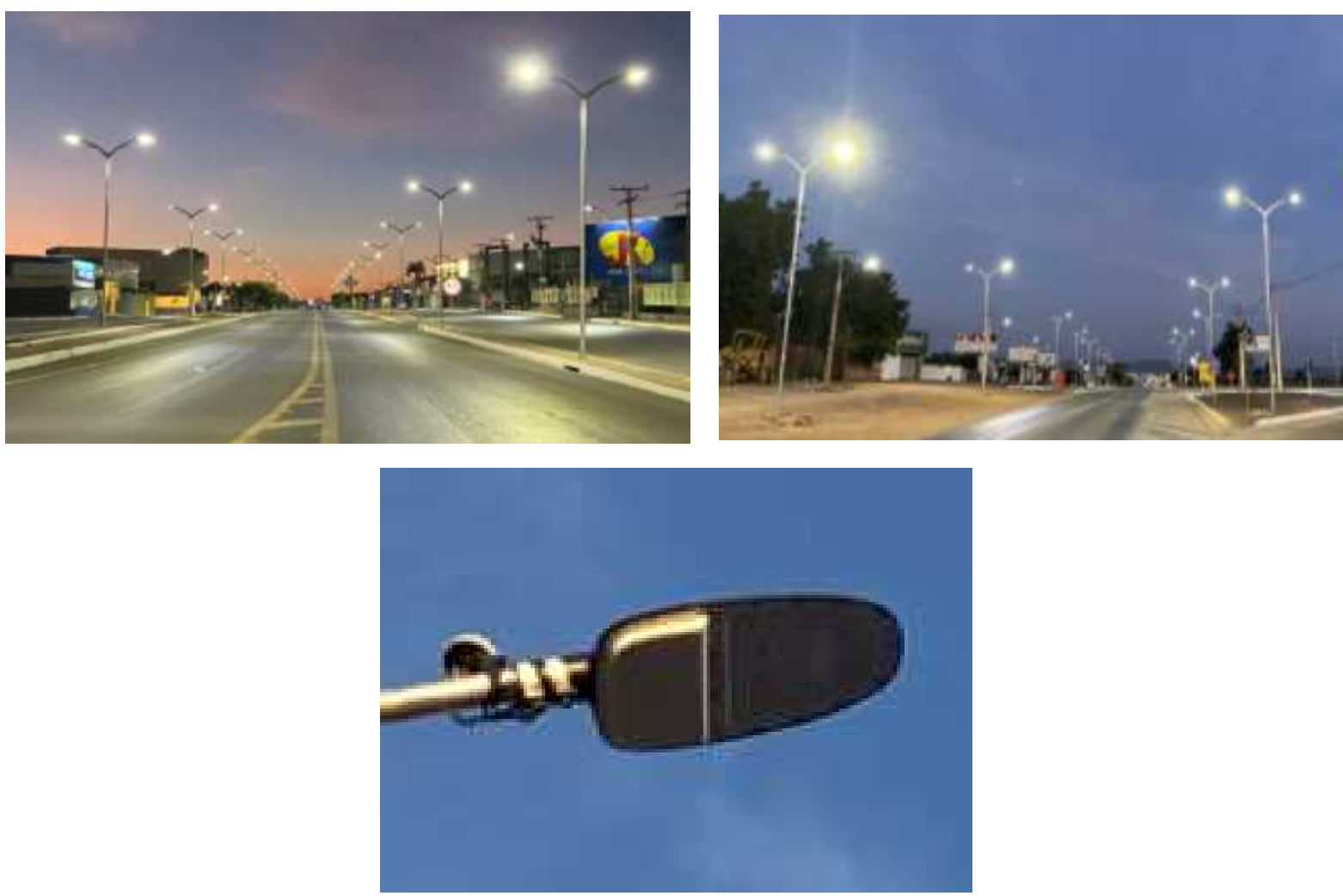

Fonte: Elaborada pelos autores deste artigo (2021)

Nesse mercado inovador, existem luminárias públicas envolvendo tecnologias modernas e em constante evolução, como a tecnologia da lâmpada LED, e outras funcionalidades postas individualmente ou associadas. Alguns exemplos das tecnologias usadas são: relé fotoelétrico que controla o funcionamento da luminária, apenas no período noturno; placa solar que fornece energia elétrica limpa para seu funcionamento e, independentemente do suprimento de energia elétrica da concessionária local, sensores de presença que permitem identificar a presença $e$ o fluxo de pessoas ou veículos na via, ajustando a luminosidade adequada e, principalmente, reduzindo a luminosidade nos períodos sem fluxo pela madrugada; sistema de câmera de segurança, visando monitorar e registrar o fluxo de movimento naquele perímetro; sistema de sinal wi-fi para integração dos sistemas e com roteadores para permitir o acesso público e social a internet pela população; além de sistema de monitoramento em tempo real da performance dos pontos de iluminação pública, isso tudo alinhado à aplicação dos conceitos de Internet das 
Coisas e de cidade inteligente. A Internet das Coisas surgiu para explicar a convergência de múltiplas tecnologias que envolvem a comunicação sem fio, internet, sistemas embarcados $e$ microeletromecânicos (OLIVEIRA et al., 2016).

Anthopoulos (2017) reuniu as propostas de outros autores para a elaboração de uma definição de Cidade Inteligente, baseada em componentes predominantemente relacionados a infraestruturas de rede e protocolos de comunicação. Nessa definição, Cidade Inteligente é entendida como o espaço urbano que utiliza as Tecnologias de Informação e Comunicação (TICs) em proveito de aplicações relacionadas ao entorno, em sua gestão, nos seus serviços inteligentes, no tratamento de dados e nos seus negócios. Estudos de Pellicer et al. (2013) e de Fu e Zhang (2017) apontam a técnica de comunicação elétrica e a mobilidade urbana como aspectos tecnológicos relacionados a cidades inteligentes.

O mercado de iluminação pública, vinculado ao conceito de cidade inteligente, tem se mostrado altamente inovador e com a intensa competitividade entre as empresas, muitas dessas configurações de luminárias públicas têm tido sua propriedade intelectual protegida por meio de patente. Ter a patente de um produto significa ter o direito de impedir terceiros de produzir, usar, colocar à venda, vender ou importar, sem o seu consentimento, o produto objeto de patente e, ainda, poder conceder licença de sua patente a terceiros, mediante remuneração ou não. A documentação de patentes é a mais completa entre as fontes de pesquisa técnica, estudos revelam que $70 \%$ das informações tecnológicas contidas nesses documentos não estão disponíveis em qualquer outro tipo de fonte de informação (INPI, 2021). A Classificação Internacional de Patentes (CIP), que é uma importante ferramenta para indexação de patentes de invenção e modelo de utilidade, foi estabelecida pelo Acordo de Strasbourg em 1971 e provê um sistema de linguagem independente de símbolos para a categorização dos documentos, de acordo com as diferentes áreas tecnológicas às quais eles pertencem, uma nova versão da CIP entra em vigor a cada ano em $1^{\circ}$ de janeiro (WIPO, 2021).

Diante do exposto, para que se possa desenvolver e introduzir com êxito um produto inovador no mercado, no caso uma Luminária Pública Multifuncional Inteligente, foi realizado um estudo de prospecção nas bases de patentes nacional e internacionais das tecnologias que compõem um produto em sua apresentação individual ou de performance múltipla, visando assegurar que o produto que será desenvolvido seja único, diferindo de qualquer produto anterior.

\section{Metodologia}

A prospecção tecnológica foi realizada com o objetivo de verificar a anterioridade e de apresentar a visão das tecnologias existentes e, a partir de então, desenvolver a Luminária Pública Multifuncional Inteligente. A busca concentrou-se nas palavras-chave dos principais itens em destaque que irão compor o equipamento inovador: Luminária Pública, utilizando lâmpada LED (diodo emissor de luz) com lente, suprida por energia Solar, com Câmera de videomonitoramento integrada, sistema de armazenamento de energia com Bateria, sistema de Som ou radiodifusão, sistema Wi-fi para interface e oferta de sinal público, incluindo frequências $5 \mathrm{G}$, Fotocélula, sistema de Controle da luminosidade e acionamento eletrônico, incluído Sensores de temperatura, pressão barométrica, umidade relativa, sistema de Armazenamento de dados coletados, inclui Software de Monitoramento e Análise de Vídeo em Tempo Real, com APP 
aplicativo para acesso via mobile, sistema de Alertas metálicas para dissipação calor e, ainda, com Medidor de fluxo bidirecional de energia elétrica caso conectado à rede elétrica da concessionária. Foi realizada inicialmente uma pesquisa bibliográfica geral sobre o tema, em algumas plataformas de publicações científicas, a exemplo do portal de periódicos CAPES/MEC, CAFE, envolvendo as palavras luminária pública e as tecnologias envolvidas.

Para avaliação do estado da técnica dos dispositivos que compõem a Luminária Pública Multifuncional Inteligente, foram escolhidas as bases de informações de patentes que subsidiam a identificação de tendências tecnológicas, o desenvolvimento de novas tecnologias e o monitoramento de concorrentes (INPI, 2021).

A prospecção tecnológica foi iniciada com a pesquisa na base de dados de patentes do Instituto Nacional da Propriedade Industrial (INPI), que contém os documentos depositados no Brasil, com o intuito de obter uma primeira visão a nível nacional e de realizar algumas simulações das palavras-chave, dos campos de pesquisa e dos códigos da CIP mais adequados.

Para uma pesquisa mais abrangente, recorreu-se às bases internacionais de patentes, como a base gratuita do Escritório Europeu de Patente (EPO - Espacenet), que possui mais de 120 milhões de documentos de mais de 100 países, incluindo os de pedidos depositados no Brasil (INPI, 2020), e também a ferramenta de busca do Questel Orbit, que é uma ferramenta comercial com desempenho muito superior ao das bases gratuitas, proporcionando a exportação $e$ o manuseio de dados em diversas extensões de arquivos, além de possuir a maior quantidade de conectores e de operadores de truncamento, o que permite ainda realizar o tratamento dos resultados mediante tabelas e gráficos de maneira rápida e eficiente (GUERREIRO et al., 2018).

As pesquisas para as três bases foram realizadas inicialmente no campo TÍTULO (Title), expandida na sequência para incluir o campo RESUMO (Abstract) e utilizando as palavras-chave: 1) LUMINÁRIA PÚBLICA (Street Light); 2) LED (Led); 3) SOLAR (Solar); 4) CÂMERA (Camera); e 5) WI-FI (Wi-fi), com o operador .AND., com o propósito de identificar processos de patentes semelhantes e que apresentem de forma cumulativa, parcial ou total as tecnologias mencionadas. Além das palavras-chave, foi também utilizada a Classificação Internacional de Patentes (CIP) em inglês International Patent Classification (IPC) - das invenções, que são definidas de acordo com o segmento da indústria, da técnica ou da atividade humana. Analisando os códigos da CIP existentes, identificou-se que a Luminária Pública Multifuncional Inteligente apresentou maior aderência na seção F (Engenharia Mecânica, Iluminação, Aquecimento, Armas, Explosão), na Classe 21 (Iluminação), Subclasse V (detalhes ou características de funcionamento dos dispositivos ou sistemas de iluminação, combinações estruturais de dispositivos de iluminação com outros artigos, não incluídos em outro local), podendo também eventualmente ser identificada em outras subclasses. Logo, a classificação IPC F21V - Detalhes ou características de funcionamento dos dispositivos ou sistemas de iluminação, combinações estruturais de dispositivos de iluminação com outros artigos, não incluídos em outro local, foi a adotada na pesquisa, visto que apresentou maior coerência com a descrição e as informações disponíveis no site do INPI.

Os resultados obtidos no INPI foram analisados e subsidiaram novas pesquisas no Orbit com resultados apresentados de forma gráfica para, assim, estudar em detalhes cada uma das quatro tecnologias envolvidas, conhecendo os principais países depositários, a cronologia do depósito dessas patentes e as principais empresas detentoras dessas patentes. Repetiu-se essa pesquisa no Orbit, porém com todas as quatro tecnologias juntas, apresentando os resultados encontrados em gráficos, análises e comentários. 
Para a busca de possíveis patentes semelhantes à Luminária Pública Multifuncional Inteligente, de forma mais ampla possível, recorreu-se de forma simultânea às bases internacionais de patentes Espacenet e Orbit, pesquisando as patentes que apresentem as tecnologias de forma isolada e, principalmente, as que apresentaram tecnologias cumulativas. As patentes selecionadas foram analisadas, observando-se em detalhes cada tecnologia empregada para compor o produto e verificando-se a descrição e as características técnicas construtivas, os desenhos ilustrativos e, em especial, as suas reinvindicações.

\section{Resultados e Discussão}

A busca bibliográfica em plataformas de publicações científicas não mostrou ser eficiente para o assunto, pois foram encontrados poucos artigos sobre iluminação em geral e muito pouco sobre iluminação pública, isso ainda sem envolver as tecnologias embarcadas, não nos direcionando apropriadamente para a elaboração do conjunto de palavras-chave para a pesquisa nas Bases de Patentes. Inferiu-se que esse resultado se deu devido ao tema ser essencialmente aplicado à produto comercial e de interesse restrito às empresas e indústrias, não sendo de visualização para a comunidade científica. Essa observação se vincula ainda à pequena percepção e à participação das empresas para parcerias com institutos de pesquisas e com universidades para o desenvolvimento de inovações aplicáveis.

A seguir são apresentados os resultados da prospecção tecnológica utilizando as bases de dados do INPI, do Escritório Europeu de Patente (EPO - Espacenet) e também da ferramenta de busca Questel Orbit.

\subsection{Base de Patentes do INPI}

A consulta foi realizada na base de dados de Patentes do INPI, em maio de 2021, utilizando as combinações das palavras-chave a seguir: Luminária, Pública, LED, Solar, Câmera, no campo de pesquisa "Titulo" e também combinada com os códigos IPC F21 e F21V, (Tabela 1). Para as combinações "luminária pública led" e "luminária pública led solar câmera", não foram encontrados resultados. O elevado número, 760 processos para Luminária, já era esperado, visto que envolve todos os tipos de luminárias, como as decorativas, as embutidas, as pendentes, as internas, além da própria luminária pública objeto deste trabalho.

A análise dos 23 processos encontrados com as palavras "luminária pública" aponta que 10 deles são recentes de 2014 a 2019, os 13 outros são de anos anteriores a 2010 e três destes mais antigos não têm nem o código CIP. A maioria desses processos trata de detalhes construtivos das luminárias como conexão, engate, suporte, fotocélula, braço giratório, retração, rebaixamento, ornamentação, porém destacam-se as três patentes mais recentes: BR1020170261514, relacionada à energia solar; e as patentes BR1020190214317 e BR02020170088265, com câmera de vigilância inclusa, para análise detalhada, pois elas possuem em separado duas tecnologias que integram a Luminária Pública Multifuncional Inteligente.

Os 12 processos com IPC F21V e os quatro com IPC F21S, que correspondem a 69,5\%, confirmam que estes Códigos, IPC F21 e F21V, são os mais indicados para continuar as pesquisas nas bases de patentes internacionais, pois representam os dispositivos ou os sistemas de iluminação de interesse para o desenvolvimento da inovação proposta. 
Tabela 1 - Dados patentários extraídos da base de dados do INPI, relativos às principais tecnologias orientadoras para a construção da Luminária Multifuncional Inteligente

\begin{tabular}{|c|c|c|c|c|}
\hline Palavras-chaves (Título) & Patentes & Modelo de Utilidade & $\begin{array}{l}\text { Códigos CIP } \\
\text { (QuANTIDADE) }\end{array}$ & TotaL \\
\hline LUMINÁRIA & & & & 760 \\
\hline LUMINARIA PÚBLICA & 11 & 12 & $\begin{array}{c}\text { F21V (12) F215(04) } \\
\text { HO5B }(02) \\
\text { HO4W(01) } \\
\text { F16L (01) }\end{array}$ & 23 \\
\hline LUMINÁRIA PÚBLICA SOLAR & 1 & 0 & & 1 \\
\hline LUMINÁRIA PÚBLICA CÂMERA & 2 & 0 & $\mathrm{~F} 21 \mathrm{~V}(01) \mathrm{F} 215(01)$ & 2 \\
\hline
\end{tabular}

Fonte: Elaborada pelos autores deste artigo, com base nos dados obtidos no INPI (2021)

\subsection{Análise das Tecnologias que Serão Utilizadas na Luminária Pública Multifuncional Inteligente Realizada de Forma Individualizada}

Os resultados das pesquisas apresentadas pela plataforma Orbit encontraram um maior número de dados em relação ao Espacenet, por isso, optou-se por utilizar os dados obtidos com o Orbit para as análises individuais (Gráficos 1, 2, 3 e 4). A análise individual de cada uma das quatro tecnologias, LED, Solar, Camera, Wi-fi, aplicadas à Luminária Pública, foi realizada para se conhecer o histórico ou a cronologia de uso dessas tecnologias, bem como os principais países que registraram as patentes. Os Gráficos 1, 2, 3 e 4 mostram os resultados obtidos no Orbit, quando se associou cada tecnologia, LED, Solar, Camera e Wifi, relacionados ao código IPC F21-Iluminação.

Gráfico 1- País de origem e ano de depósito de patentes relativas à tecnologia LED, associada à iluminação pública, com código IPC F21

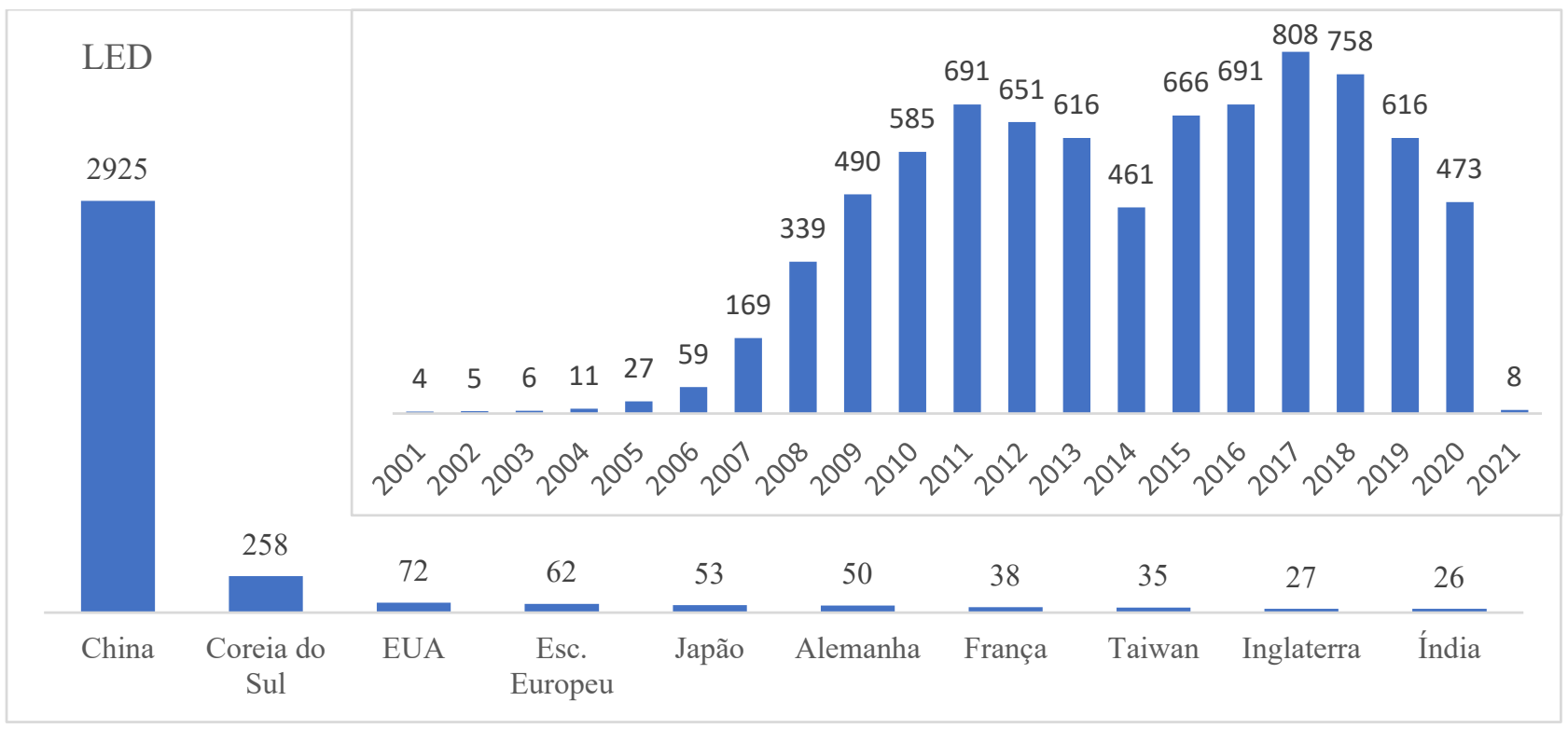

Fonte: Elaborado pelos autores deste artigo, com base nos dados obtidos no Orbit (2021)

Na análise dos países que mais depositaram, foram consideradas as patentes ativas, 3.743, representando $45,9 \%$ das 8.142 patentes totais. O resultado mostra que a tecnologia LED asso- 
ciada à iluminação pública é totalmente dominada pela China, que aparece como o principal país depositante, com 2.925 registros, 78,1\% do total, número bem superior se comparado ao resto do mundo. O segundo país mais representativo é a República da Coreia ou Coreia do Sul, com 258 registros ou $6,9 \%$, também considerada uma nova potência tecnológica, que, no final da década de 1980, teve por questões estratégicas seus maiores parceiros os EUA e o Japão, tanto comercial para importação e exportação de produtos quanto a elevados investimentos e transferência de conhecimento inovador tecnológico (VIEIRA; PENNA, 2020). Em seguida, estão outros países com grande desenvolvimento em tecnologia, como EUA com 72 patentes (1,9\%), Japão com 53 (1,4\%) e Alemanha com 50 (1,3\%), além do Escritório Europeu de Patentes destacando-se em quarto lugar com 62 patentes (1,7\%), que, desde 1977, representa a base europeia de patentes.

Quanto à cronologia, pode-se observar no Gráfico 1 que LED se trata de uma tecnologia relativamente recente, tendo um incremento no número de patentes a partir de 2008, apresentando duas ondas crescentes, a primeira entre os anos 2010-2012 e a segunda maior entre 20162018, registrando um decréscimo anual desde então. A lâmpada LED substituiu com sucesso as tecnologias anteriores de vapor metálico, com redução do consumo de energia, maior vida útil e redução dos custos de manutenção, sendo uma tecnologia limpa e que ainda permite a integração com sistemas eletrônicos de controle e operação.

A análise do Gráfico 2 se refere às 2.232 patentes ativas, 52,0\% das 4.306 patentes totais, e mostra que a tecnologia de energia Solar associada à iluminação pública também é dominada pela China, com 2.075 patentes ou 92,7\%, seguida a distância pela Coreia do Sul com 111 patentes ou 5,0 \%, e também é uma tecnologia recente que teve um discreto acréscimo contínuo a partir de 2006 e um forte incremento entre 2015-2017, registrando um decréscimo desde então. Trata-se de uma fonte de energia alternativa, limpa, renovável e gratuita e com expectativa de vida útil superior a 25 anos para os sistemas de geração de energia com sistemas fotovoltaicos.

Gráfico 2 - País de origem e ano de depósito das patentes relativas à tecnologia Solar, associada à iluminação pública, com código IPC F21

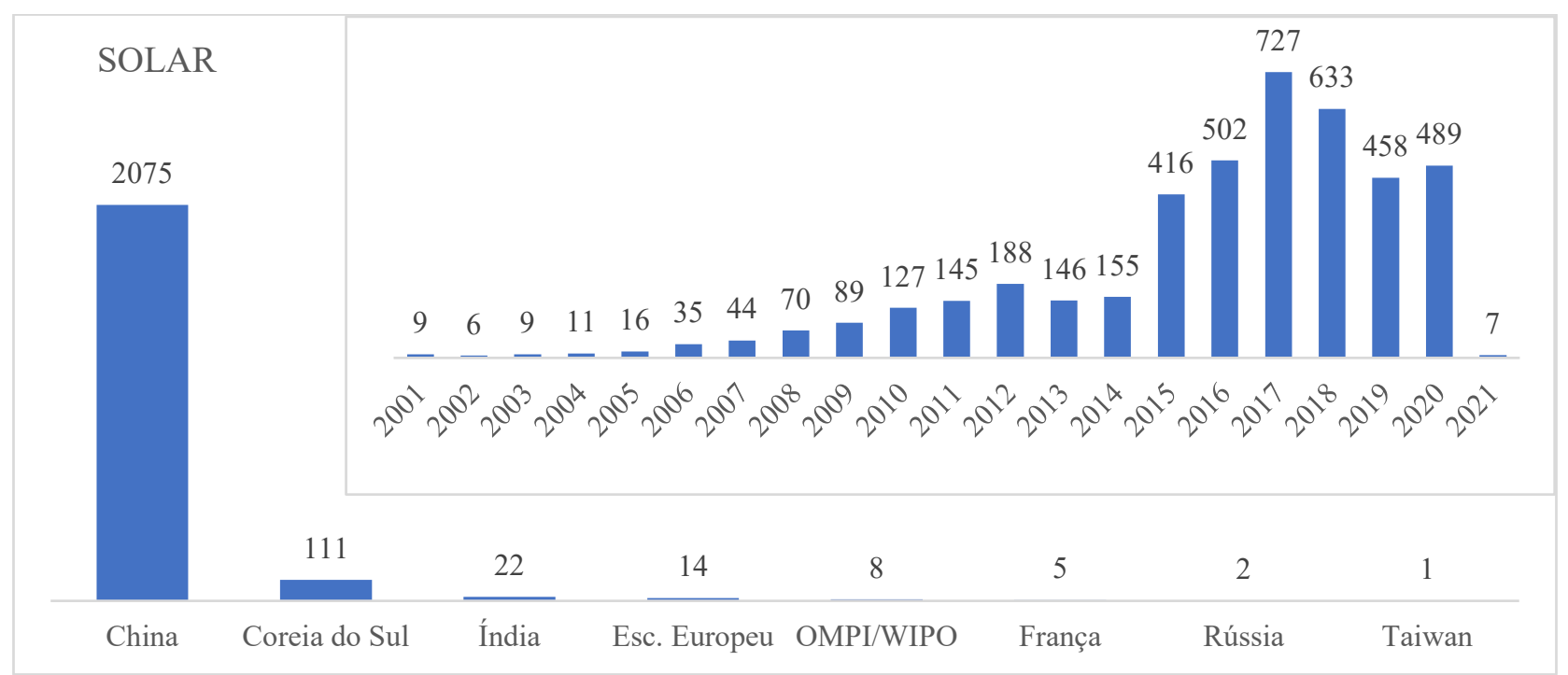

Fonte: Elaborado pelos autores deste artigo, com base nos dados obtidos no Orbit (2021) 
O Gráfico 3 se refere às 193 patentes ativas, 60,9\% das 317 patentes totais, mostrando que a tecnologia de Câmera de videomonitoramento associada à iluminação pública também é dominada pela China, com 155 patentes ou 80,31\%, seguida a distância pela Coreia do Sul com 20 patentes ou 10,36\%. Essa tecnologia também é recente, aparecendo a partir de 2008, tendo um forte incremento entre 2015-2018, registrando um decréscimo desde então. Esse recente incremento pode ser justificado pelo aumento da violência e pelas preocupações com a segurança das pessoas e do patrimônio, o que veio a valorizar a vigilância eletrônica e estimular o mercado. Essa tecnologia permite monitoramento em tempo real, armazenamento de imagens e interface com sistemas inteligentes de reconhecimento de placas de veículos ou facial, e sua integração na iluminação pública tem inovado as opções de instalação dessas câmeras nas áreas externas, antes limitadas às fachadas dos imóveis.

Gráfico 3 - País de origem e ano de deposito das patentes relativas à tecnologia Câmera, associada à iluminação pública, com código IPC F21

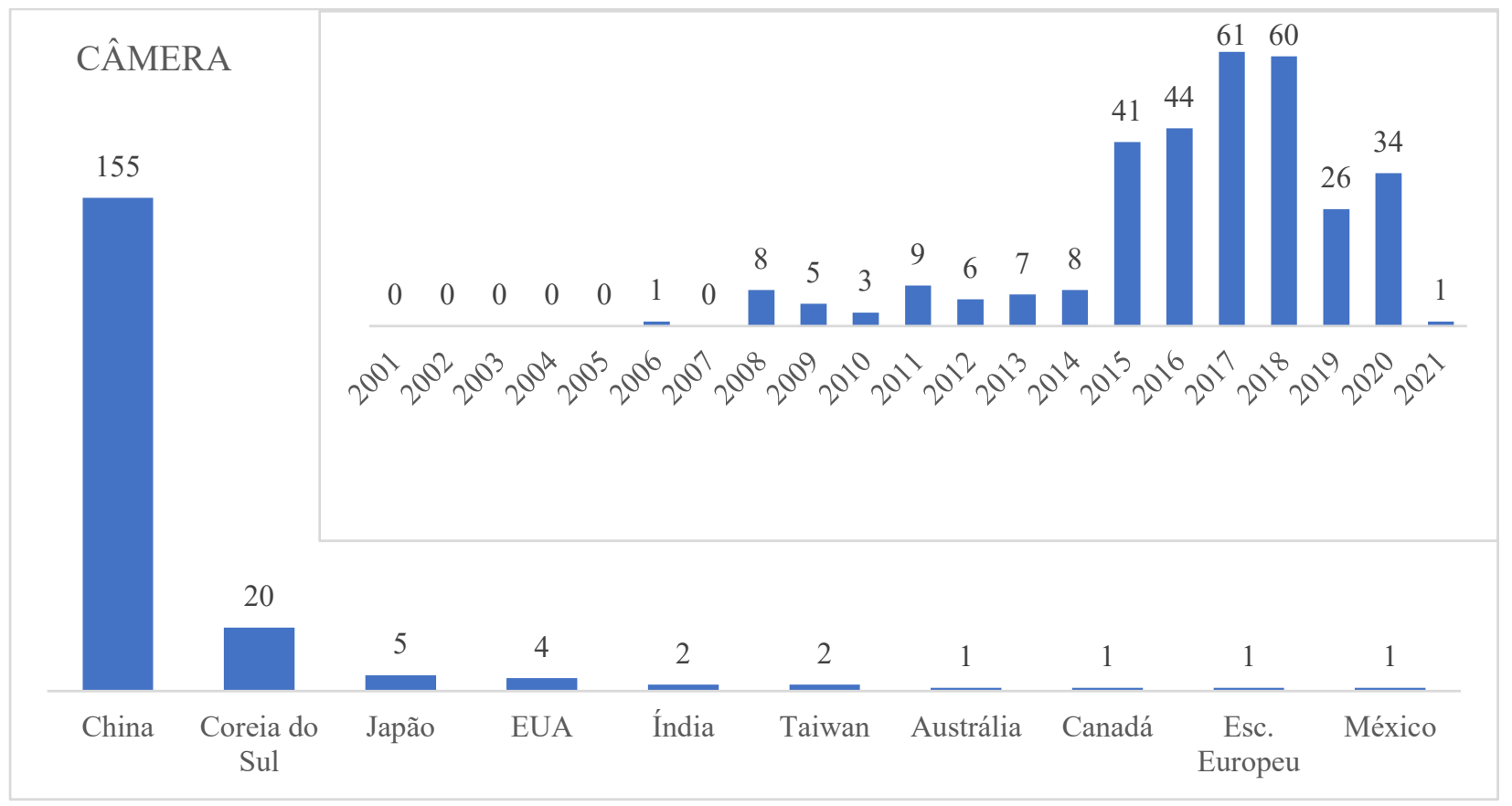

Fonte: Elaborado pelos autores deste artigo, com base nos dados obtidos no Orbit (2021)

A análise do Gráfico 4 se refere às 32 patentes ativas, $56,1 \%$ das 57 patentes totais, e nos mostra que a tecnologia Wi-fi associada à iluminação pública também é dominada pela China com 30 patentes ou 93,8\%, seguida a distância pela Coreia do Sul, com duas patentes ou 6,2\%, se limitando a esses dois países, e também é muito recente, tendo a primeira patente surgida em 2012, com forte incremento entre 2015-2018, registrando um decréscimo desde então. $\mathrm{O}$ acesso à internet fora do ambiente de trabalho ou em casa tem sido cada dia mais comum e necessário para a população, o que tem justificado os investimentos crescentes em sistemas públicos de internet sem fio (Wi-fi), normalmente em praças, pontos de ônibus e em locais de concentração de pessoas, e a opção de instalação dos roteadores de internet Wi-fi integrados à iluminação pública tem sido uma alternativa para a expansão desses sistemas, além de permitir a comunicação e a integração entre os sistemas. 
Gráfico 4 - País de origem e ano de deposito das patentes relativas à tecnologia Wi-fi, associada à iluminação pública, com código IPC F21

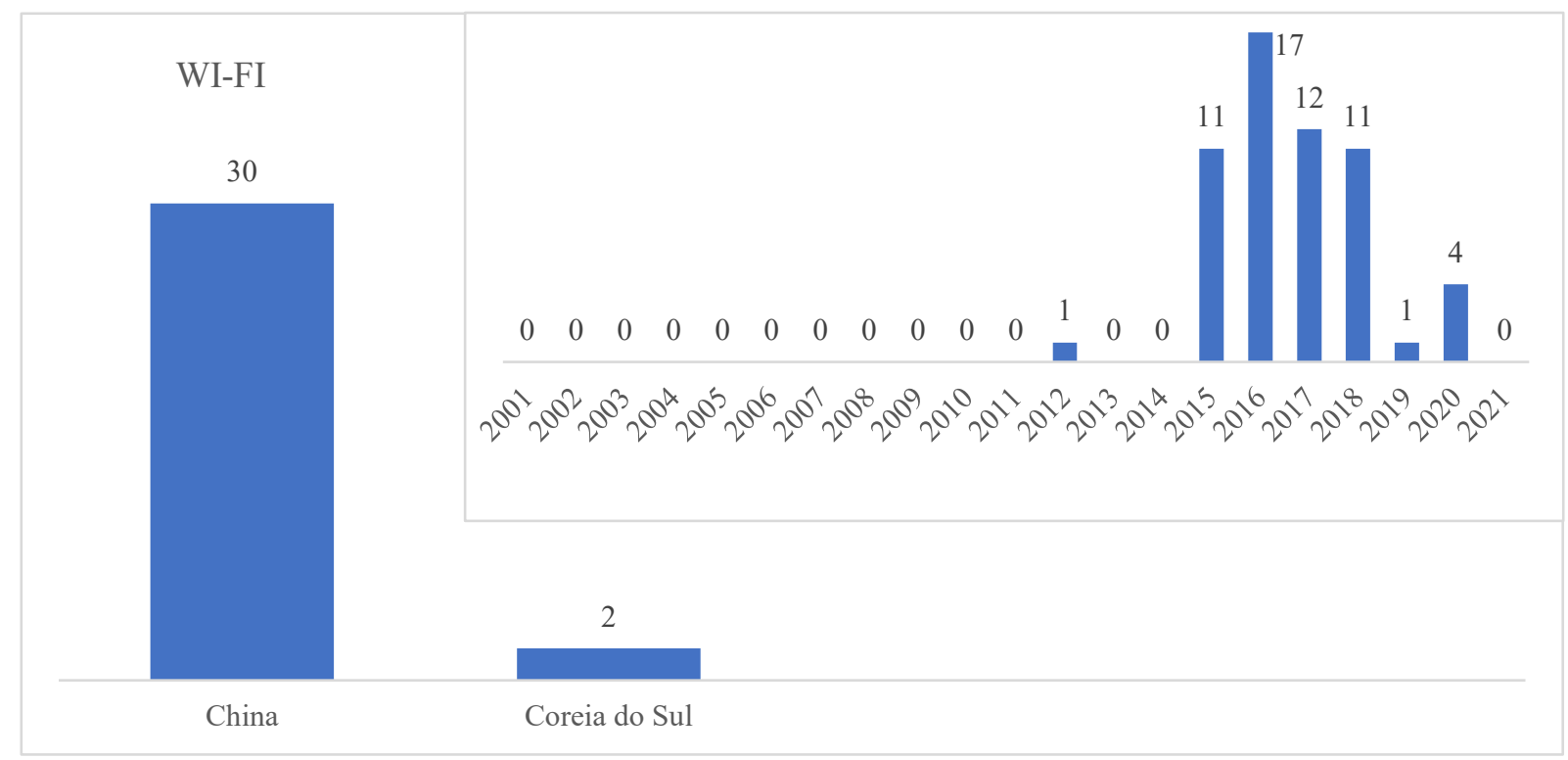

Fonte: Elaborado pelos autores deste artigo, com base nos dados obtidos no ORBIT (2021)

\subsection{Análise das Tecnologias que Serão Utilizadas na Luminária Pública Multifuncional Inteligente Realizada de Forma Conjunta}

A análise conjunta das tecnologias LED, Solar, Câmera, Wi-fi, aplicadas à Luminária Pública permitiu o conhecimento do histórico ou da cronologia de uso dessas quatro tecnologias, bem como os principais países e as empresas que mais registraram as patentes, associados ao código IPC F21-Iluminação (Gráfico 5). A pesquisa realizada no sistema Orbit nos campos Título e Resumo ficou com a seguinte combinação: ((LIGHT AND STREET)/TI/AB AND (LED OR SOLAR OR CAMERA OR WIFI)/TI/AB) AND (F21 \#)/IP e retornou 10.590 registros. Ressalta-se que a quantidade de patentes ativas foi de 5.188 patentes, $49,0 \%$ das patentes encontradas.

Gráfico 5 - Ano de depósito das patentes relativas às tecnologias LED, Solar, Câmera, Wi-fi, associadas à iluminação pública, com código IPC F21

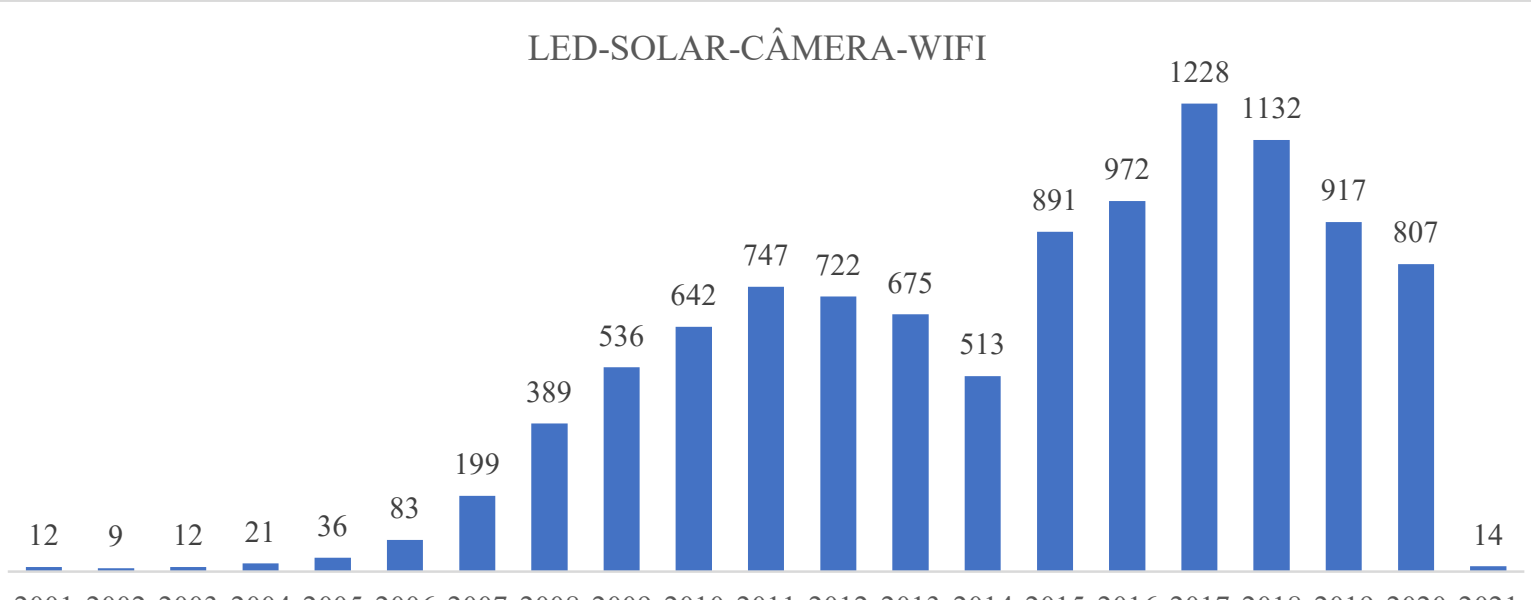

200120022003200420052006200720082009201020112012201320142015201620172018201920202021

Fonte: Elaborado pelos autores deste artigo, com base nos dados obtidos no Orbit (2021) 
A análise dessas 5.188 patentes ativas mostra que a aplicação das tecnologias LED, Solar, Câmera e Wi-Fi, quando estas são avaliadas em conjunto e relacionadas à iluminação pública, também é recente, e um considerável incremento no número de registros pode ser observado a partir de 2007, com duas ondas se destacando entre 2009-2013 e 2015-2019. Esse comportamento reflete a análise feita para as tecnologias isoladas, sendo que o pico maior da segunda onda pode ser explicado pelo fato de essas tecnologias terem evolução constante e de terem se tornado mais eficientes a cada dia, permitindo novas opções de aplicação e de inteiração entre elas.

Destacam-se no Gráfico 6 que as 15 principais instituições das 1.249 que detêm as 5.188 patentes ativas relativas às tecnologias LED, Solar, Câmera, Wi-Fi, associadas à iluminação pública, são sediadas na China e na Coreia do Sul, sendo que o maior player do mercado é a empresa chinesa XI AN ZHIHAI POWER TECHNOLOGY, com 35 dessas patentes ou 0,7\%, e que ainda detém um total de 615 patentes de invenção, incluindo 154 patentes ativas, seguida pela empresa também chinesa XI AN BOYU GREEN ENERGY com 26 patentes ativas ou 0,5\%. Vale destacar que para Freire, Guimarães e Jesus (2011), o sucesso na estratégia competitiva de determinada indústria depende também da prospecção e do monitoramento de informações sobre determinado processo ou tecnologia.

Gráfico 6 - Principais empresas detentoras das patentes relativas às tecnologias LED, Solar, Câmera, Wi-fi, associadas à iluminação pública, com código IPC F21

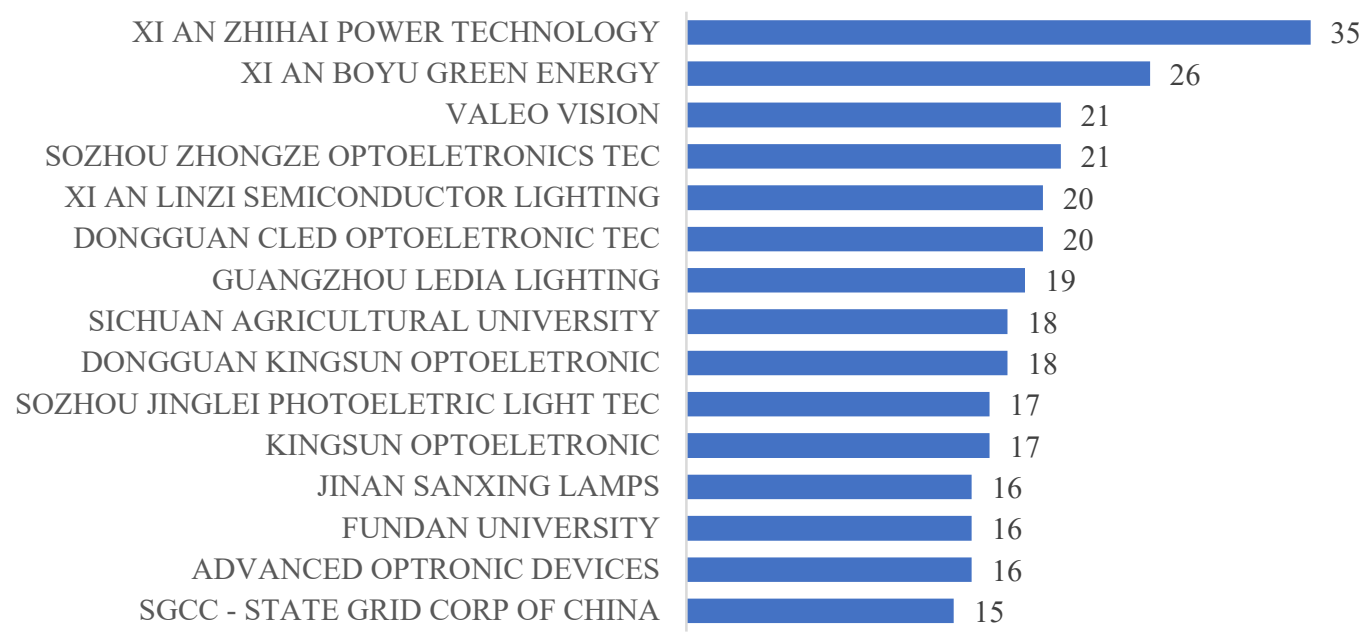

Fonte: Elaborado pelos autores deste artigo, com base nos dados obtidos no Orbit (2021)

Interessante observar que, entre essas 15 principais instituições, aparecem duas Universidades Chinesas, a SICHUAN AGRICULTURAL UNIVERSITY, localizada na Província de Sichuan, especializada em biotecnologia e ciências agrícolas, e a FUNDAN UNIVERSITY, localizada em Xangai, e é uma das universidades mais antigas e de maior prestígio na República Popular da China. A observação da presença das universidades nesse ranking de empresas tecnológicas demonstra a existência da maturidade governamental, que provavelmente tem muito bem definido em seu arcabouço de políticas públicas o incentivo à inovação, motivando as empresas a estabelecerem parcerias.

Dos países que dominam as 5.188 patentes ativas relacionadas às Tecnologias LED, Solar, Câmera, Wi-fi, associadas à iluminação pública, a China lidera com 4.170 registros ou 80,4\%, seguida a distância pela Coreia do Sul, com 343 patentes ou 6,6\%, EUA 84 (1,6\%), Escritório 
Europeu de Patentes 74 (1,4\%) Japão 67 (1,3\%) e Alemanha 53 (1,0\%), representadas no Gráfico 7, que acompanha o mapa de calor, destacando esses países pela coloração mais forte.

Gráfico 7 - País de origem das patentes relativas às tecnologias LED, Solar, Câmera, Wi-fi, associadas à iluminação pública, com código IPC F21

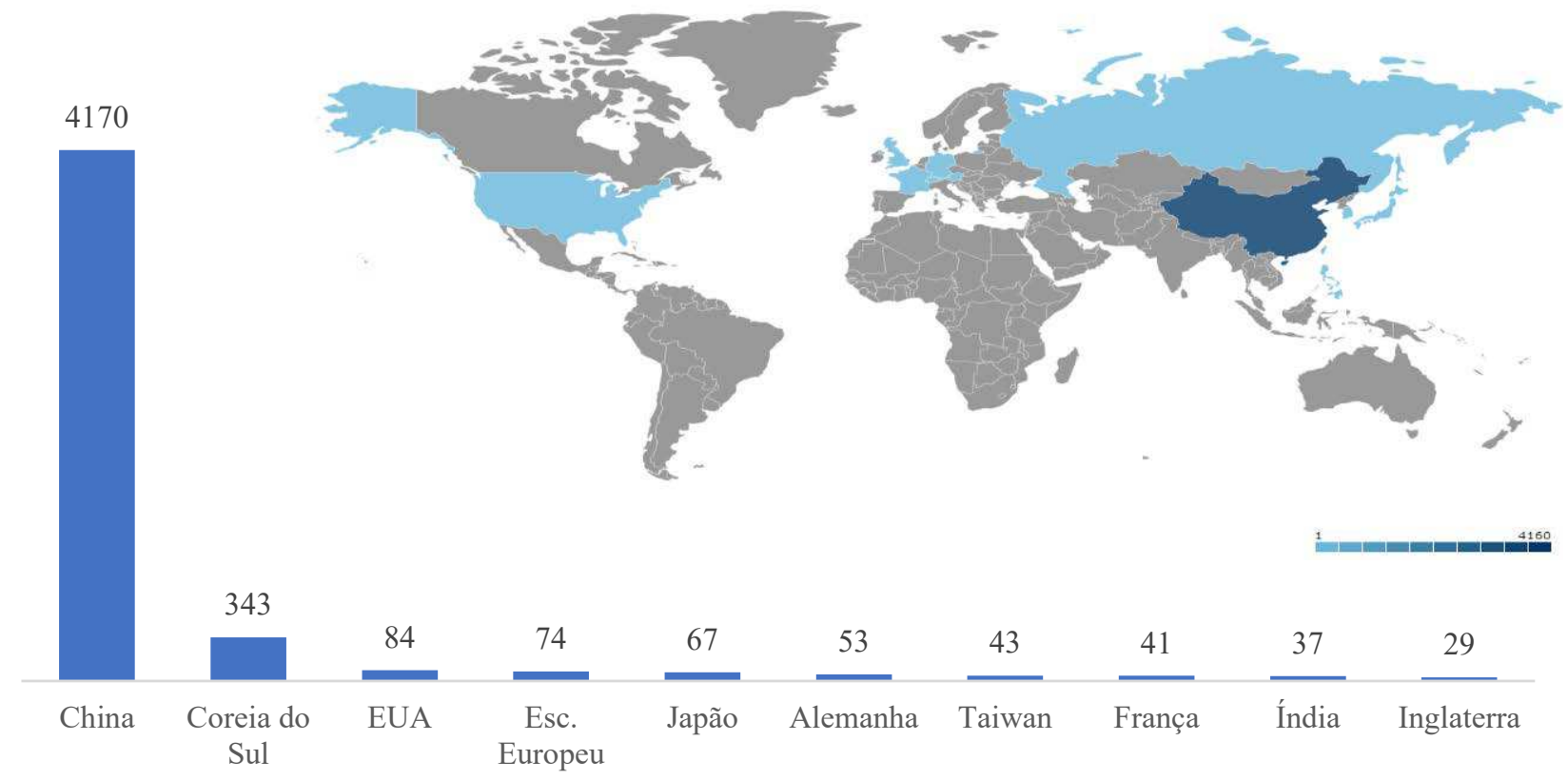

Fonte: Elaborado pelos autores deste artigo, com base nos dados obtidos no Orbit (2021)

Nesse ranking, o Brasil aparece em $23^{\circ}$ lugar com sete patentes ativas, sendo que apenas duas delas são nacionais, BR20201700098 e a BR202013016568, e as outras cinco são originadas em outros países e com proteção no Brasil, EP2481979, EP2581640, EP2791575, EP3072366 e US9933145.

\subsection{Refinando a Análise das Patentes: Espacenet, Orbit Intelligence}

Com o propósito de buscar possíveis patentes contendo as tecnologias que estarão envolvidas no projeto da Luminária Pública Multifuncional Inteligente, as pesquisas foram realizadas simultaneamente nas bases internacionais de patentes Espacenet, Orbit Intelligence, utilizando as combinações das palavras-chave como indicado a seguir: STREET LIGHT, LED, SOLAR, CAMERA, WIFI no campo de pesquisa "Title", com o operador .AND. e também combinadas com os códigos IPC F21 e F21V (Tabela 2).

Foi encontrado elevado número, mais de 10.000 processos, quando se utilizou apenas luminária (LIGHT), com os códigos F21V, F21, como também não se encontrou nenhum resultado quando foram associadas estas principais funcionalidades: LED, Solar e Câmera em um único produto, isso nas duas bases de patentes (Tabela 2).

$\mathrm{Na}$ base Espacenet, ao direcionar para Luminária pública (STREET LIGHT), reduziu-se bastante o número de patentes encontradas, ficando entre 3.264 a 4.865 processos, e associados às principais tecnologias, foram encontrados estes números: de 2.128 a 2.530 para LED; de 356 a 558 para solar e poucos processos de oito a 15 para a tecnologia câmera. 
A pesquisa semelhante na base Orbit Intelligence apresentou o número de processos pouco acima dos números do Espacenet, porém mantendo certa proporcionalidade, como observa-se nas pesquisas com os códigos F21V, F21, que, direcionado para Luminária pública (STREET LIGHT), a amostra fica bastante reduzida, entre 3.527 a 5.361 processos, que associados às principais tecnologias, obteve-se: de 2.230 a 2.666 para LED, de 383 a 606 para solar, apenas quatro a 14 processos para câmera.

Tabela 2 - Dados patentários extraídos da base de dados do Espacenet e do Orbit Intelligence, relativos às principais tecnologias da Luminária Multifuncional Inteligente

\begin{tabular}{|c|c|c|c|c|c|c|}
\hline \multirow[b]{2}{*}{ Palavras-chave (TITLE) } & \multicolumn{3}{|c|}{ ESPACENET } & \multicolumn{3}{|c|}{ OrBit } \\
\hline & $\begin{array}{l}\text { SEM } \\
\text { IPC }\end{array}$ & IPC F21 & $\begin{array}{c}\text { IPC } \\
\text { F21V }\end{array}$ & $\begin{array}{l}\text { SEM } \\
\text { IPC }\end{array}$ & $\begin{array}{l}\text { IPC } \\
\text { F21 }\end{array}$ & $\begin{array}{c}\text { IPC } \\
\text { F21V }\end{array}$ \\
\hline LIGHT and STREET & 4.865 & 3.724 & 3.264 & 5.361 & 4.111 & 3.527 \\
\hline LIGHT and STREET and LED & 2.530 & 2.239 & 2.128 & 2.666 & 2.356 & 2.230 \\
\hline LIGHT and STREET and SOLAR & 558 & 455 & 356 & 606 & 498 & 383 \\
\hline LIGHT and STREET and CAMERA & 15 & 11 & 8 & 14 & 8 & 4 \\
\hline
\end{tabular}

Fonte: Elaborada pelos autores deste artigo, com base no Espacenet e Orbit (2021)

Considerando os resultados obtidos nas Plataformas Espacenet e Orbit, principalmente quando se associam as três tecnologias LED, Solar e Camera, pesquisadas no campo Título, não encontrando nenhum resultado, resolveu-se ampliar as pesquisas nessas plataformas, incluindo as palavras-chave também no campo RESUMO e adicionar uma quarta tecnologia, que é o sistema de interface Wi-fi(WIFI), sempre associado aos códigos IPC F21 e F21V. Repetiu-se o mesmo padrão das pesquisas anteriores, tanto no Espacenet quanto no Orbit, e os novos resultados obtidos estão resumidos na Tabela 3.

Observa-se que o quantitativo de dados encontrados foi bem maior que os resultados das pesquisas anteriores, em todas as combinações com as tecnologias LED, Solar, Câmera e Wi-fi, visto que, conforme já esperado, as palavras-chave dessas tecnologias que não estavam contempladas no Título aparecem agora citadas no Resumo, podendo fazer parte do produto ou apenas uma referência.

Os resultados desta pesquisa foram quatro patentes encontradas pela base Espacenet $e$ cinco patentes, pelo Orbit. Esses nove documentos foram analisados em detalhes para verificar como cada uma dessas tecnologias referentes às palavras encontradas no Resumo está contemplada na invenção e se ela faz parte das reinvindicações da patente, como também analisar a descrição e os desenhos ilustrativos com os arranjos e configurações. 
Tabela 3 - Dados patentários extraídos da base de dados do Espacenet e do Orbit Intelligence relativos às principais funcionalidades da Luminária Multifuncional Inteligente, incluindo pesquisas com a tecnologia Wi-fi e as palavras-chave também no Resumo (Abstract)

\begin{tabular}{cccccccc} 
& \multicolumn{3}{c}{ ESPACENET } & \multicolumn{4}{c}{ ORBIT } \\
PALAVRAS-CHAVE (TITLE) & SEM & IPC F21 & IPC & SEM & IPC & IPC \\
LIGHT and STREET & IPC & IPC & IPC & F21 & F21V \\
LIGHT and STREET and LED & 9.090 & 7.743 & 7.321 & 9.561 & 8.142 & 7.651 \\
LIGHT and STREET and SOLAR & 4.762 & 3.956 & 3.534 & 5.154 & 4.306 & 3.808 \\
LIGHT and STREET and CAMERA & 603 & 293 & 275 & 651 & 317 & 291 \\
LIGHT and STREET and WIFI & 97 & 49 & 25 & 107 & 57 & 55 \\
$\begin{array}{c}\text { LIGHT and STREET and } \\
\text { CAMERA and SOLAR and WIFI }\end{array}$ & 4 & 3 & 3 & 5 & 3 & 3 \\
\hline
\end{tabular}

Fonte: Elaborada pelos autores deste artigo, com base no Espacenet e Orbit (2021)

$\mathrm{Na}$ análise preliminar destas nove patentes, notou-se que as quatro patentes encontradas pelo Espacenet são as mesmas e estão inclusas nas cinco patentes encontradas pelo Orbit. Em cada uma delas formam encontrados pontos e itens que as diferem da proposta da Luminária Pública Multifuncional Inteligente, cujas principais características estão destacadas na Tabela 4.Observa-se que essas cinco patentes são recentes de 2014 a 2017, sendo quatro da China e uma da Coreia do Sul, e, apesar de apresentarem algumas das tecnologias que estarão presentes na Luminária Pública Multifuncional inteligente, identificadas no Título ou no Resumo delas, ao analisar de forma mais detalhada toda a documentação da patente, incluindo a descrição, os desenhos ilustrativos e as reinvindicações, concluiu-se que não há semelhança com o produto que estará em desenvolvimento. As diferenças estão principalmente nos arranjos propostos, visto que apresentam o produto com as tecnologias em partes, ou em invólucros separados, sendo que um dos diferenciais da Luminária Pública Multifuncional Inteligente será justamente apresentar, em um único produto, todas as tecnologias citadas, funcionando de forma harmônica e compacta. 
Tabela 4 - Análise detalhada dos dados do Orbit Intelligence, relativos às principais características e diferenças dessas cinco patentes semelhantes, em relação às funcionalidades da Luminária Pública Multifuncional Inteligente

\begin{tabular}{|c|c|c|c|c|c|c|}
\hline $\begin{array}{l}\text { Patentes } \\
\text { similares }\end{array}$ & Título & Ano & País & Diferenças & Extra & Arranjo \\
\hline CN206191476 & $\begin{array}{c}\text { Complementary solar energy led } \\
\text { street lamp of multi-functional } \\
\text { scene }\end{array}$ & 2017 & China & $\begin{array}{l}\text { Os processos estão em } \\
\text { arranjos separados e não } \\
\text { integrados em um único } \\
\text { corpo(luminária) }\end{array}$ & $\begin{array}{l}\text { inclui o poste e Gerador } \\
\text { eólico, modulos externos }\end{array}$ & $=$ \\
\hline CN204404405 & $\begin{array}{l}\text { Solar photovoltaic power } \\
\text { generation led street lamp }\end{array}$ & 2015 & China & $\begin{array}{l}\text { Os processos estão em } \\
\text { arranjos separados e não } \\
\text { integrados em um único } \\
\text { corpo(luminária) }\end{array}$ & $\begin{array}{l}\text { inclui poste e uma caixa } \\
\text { fixada no mesmo }\end{array}$ & \\
\hline CN205480714 & $\begin{array}{l}\text { Novel light-emitting diode (led) } \\
\text { street lamp }\end{array}$ & 2016 & China & $\begin{array}{l}\text { Os processos estão em } \\
\text { arranjos separados e não } \\
\text { integrados em um único } \\
\text { corpo(luminária) }\end{array}$ & $\begin{array}{l}\text { inclui o poste e algumas } \\
\text { funcionalidades instaladas } \\
\text { nele }\end{array}$ & \\
\hline CN205574786 & $\begin{array}{l}\text { Wifi if bus station that takes } \\
\text { lamp house camera gps litterbin } \\
\text { that desinfects }\end{array}$ & 2016 & China & $\begin{array}{l}\text { Sistema para ponto de } \\
\text { ônibus, não se trata de } \\
\text { iluminação pública }\end{array}$ & $\begin{array}{c}\text { envolve caixa de } \\
\text { publicidade e de coleta de } \\
\text { lixo, e oferece iluminação } \\
\text { indireta }\end{array}$ & \\
\hline KR200474732 & $\begin{array}{c}\text { Security camara sistem } \\
\text { including secutity camera device } \\
\text { equipped with photovoltaic led } \\
\text { streetlight }\end{array}$ & 2014 & $\begin{array}{l}\text { Coreia do } \\
\quad \text { Sul }\end{array}$ & $\begin{array}{l}\text { Os processos estão em } \\
\text { arranjos separados e não } \\
\text { integrados em um único } \\
\text { corpo(luminária) }\end{array}$ & $\begin{array}{l}\text { sistema externo com } \\
\text { algumas tecnologias, e que } \\
\text { controla a lâmpada led }\end{array}$ & 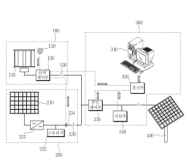 \\
\hline
\end{tabular}

Fonte: Elaborada pelos autores deste artigo, com base nos dados obtidos no Orbit (2021)

Realizou-se também outra pesquisa, mais ampla, com as tecnologias envolvidas LED, Solar, Câmera, sem o código IPC, porém pesquisando as palavras-chave nos campos Título e Resumo, com a seguinte combinação: (LIGHT AND STREET AND LED AND SOLAR AND CAMERA)/TI/ AB. O Orbit encontrou 86 patentes, com possível semelhança, e que foram analisadas também em detalhes no Resumo, nas Figuras e nas Reinvindicações (Imagem 2).

Imagem 2 - Desenhos ilustrativos das patentes integrantes da pesquisa nos 86 documentos, obtidos nos dados do Orbit Intelligence
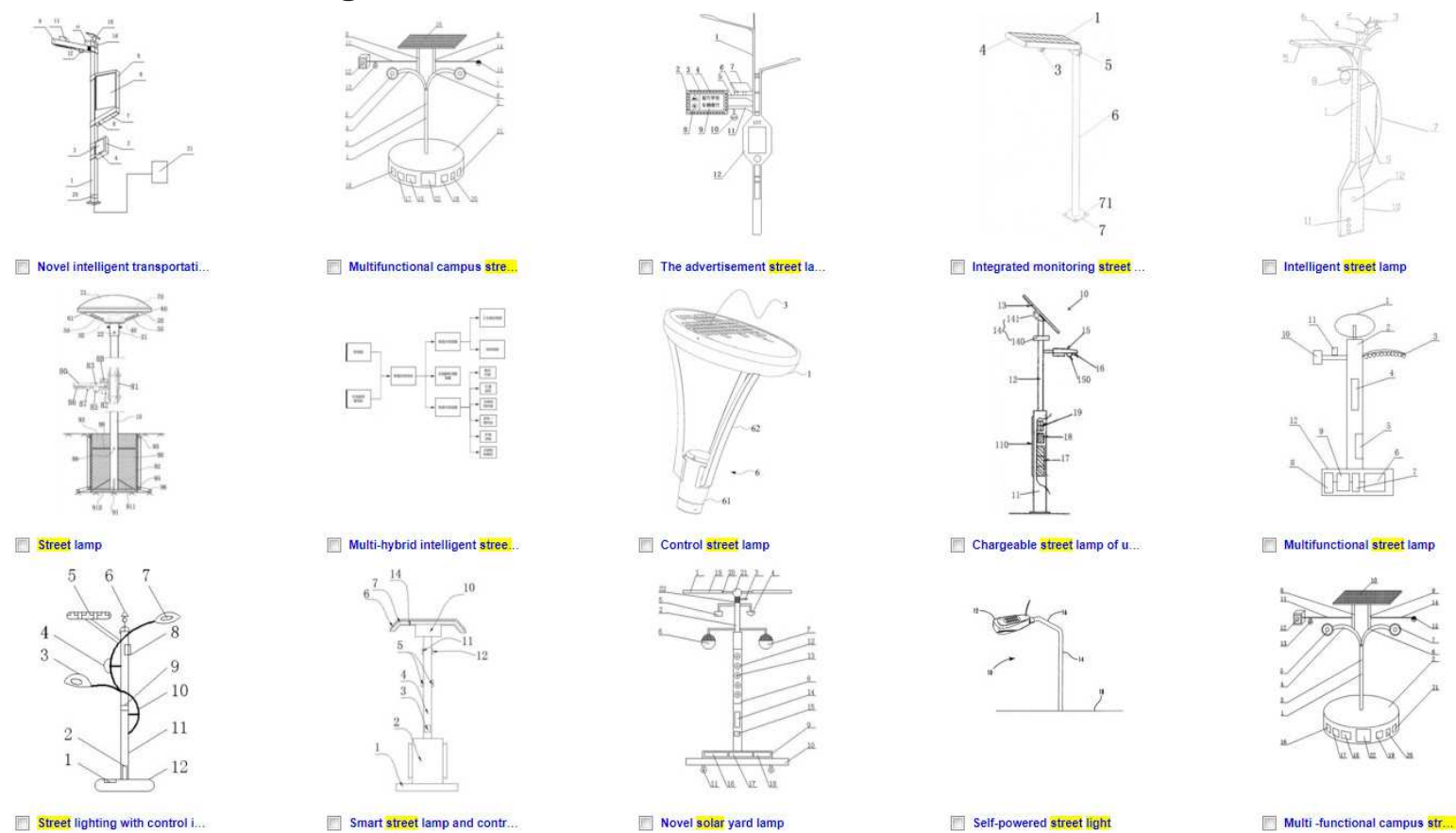

Fonte: Elaborada pelos autores deste artigo, com base nos dados obtidos no Orbit (2021) 
É possível separar o resultado desta análise em dois grandes blocos, sendo aquelas patentes que contemplam a maioria das três tecnologias em questão, porém localizadas em invólucros ou caixas externas separadas e boa parte delas anexados a uma base ou a um poste. Outra parte das patentes que apresentam um único volume da luminária pública traz apenas algumas das três tecnologias, com opções de portas de dispositivos de comunicação para conexão de dispositivos externos, como itens opcionais e não inclusos nesse involucro único da luminária pública.

Portanto, neste universo ampliado de 86 patentes, não se encontrou semelhança e muito menos coincidência, reforçando que um dos diferenciais da Luminária Pública Multifuncional Inteligente é justamente apresentar em um único produto, no caso a Luminária, todas as tecnologias citadas, funcionando de forma harmônica e compacta.

\section{Considerações Finais}

As tecnologias envolvidas analisadas em separado e também em conjunto mostraram uma interessante similaridade, tendo como característica comum o fato de serem tecnologias relativamente novas, que despontaram na última década, estando em constante desenvolvimento com o auge de crescimento no triênio 2016-2018 e decrescendo desde então. A China registrou o maior número de patentes seguida a distância pela Coreia do Sul, que juntas concentram mais de $90 \%$ desse mercado. O Brasil só aparece quando a busca considera também o resumo e está ranqueado em $23^{\circ}$ lugar, com sete patentes, sendo apenas duas nacionais. As empresas chinesas são os grandes players desse mercado, lideradas pela XI AN ZHIHAI POWER TECHNOLOGY e pela XI AN BOYU GREEN ENERGY, com destaque para as duas universidades que aparecem entre as 15 maiores empresas.

Os resultados das pesquisas ampliadas com o intuito de buscar possíveis similaridades com o produto que será desenvolvido mostraram patentes que na realidade traziam a tecnologia em invólucros ou caixas externas à luminária, ou que citavam a possibilidade de uso da tecnologia de forma opcional, o que comprova que o grande diferencial da Luminária Pública Multifuncional Inteligente é justamente apresentar em um único objeto, no caso a Luminária em si, todas as tecnologias citadas, funcionando de forma harmônica e compacta, e que essa configuração somente agora é exequível, visto a recente aplicação de nanotecnologia, Internet das Coisas, Indústria 4.0, Inteligência Artificial, aplicados a conceitos de Smart Grid e Smart Cities, e que, relacionadas entre si, têm contribuído pelo recente e exponencial desenvolvimento e evolução dessas tecnologias envolvidas, tornando-as a cada dia muito mais eficientes, melhorando sua qualidade, sua performance, seu alcance e abrangência, sua durabilidade, e, por outro lado, muito mais compactas e com menor consumo de energia.

\section{Perspectivas Futuras}

Com base na prospecção realizada, confirmando que a proposta de uma Luminária Pública Multifuncional Inteligente atende aos requisitos de novidade e atividade inventiva, será desenvolvida a patente com a premissa de aplicação industrial por se tratar de um produto cada vez mais adequado e necessário aos novos conceitos de Smart Grid e Smart Cities que utilizam as tecnologias da informação e comunicação baseadas em estrutura de rede de múltiplos propósitos 
A partir do depósito, essa tecnologia que hoje apresenta o seu nível de desenvolvimento tecnológico em TRL3 estará apta para continuar sua evolução nas próximas etapas rumo ao TRL8, estando disponível para busca de empresas parceiras no mercado nacional ou internacional, para o seu completo desenvolvimento e aprimoramento, ou então preparada e qualificada para um processo de Transferência de Tecnologia.

\section{Referências}

ABNT - ASSOCIAÇÃO BRASILEIRA DE NORMAS TÉCNICAS. NBR 5101: Iluminação Pública. Rio de Janeiro, 2018. p. 35.

ANEEL - AGÊNCIA NACIONAL DE ENERGIA ELÉTRICA. Resolução Normativa n. 414, 9 de setembro de 2010. Disponível em: http://www.aneel.gov.br/cedoc/ren2010414.pdf. Acesso em: 20 nov. 2019.

ANEEL - AGÊNCIA NACIONAL DE ENERGIA ELÉTRICA. Manual do Programa de Eficiência Energética. [2020]. Disponível em: http://www.aneel.gov.br/arquivos/PDF/aren2008300_2.pdf. Acesso em: 22 jul. 2020.

ANTHOPOULOS, L. G. The rise of the smart city. In: ANTHOPOULOS, L. G. Understanding Smart Cities: A Tool for Smart Government or an Industrial Trick. [S.l.]: Springer, Cham, 2017. p. $5-45$.

BARRERA, Alex. Forget Silicon Valley: Innovation is happening in China now. 2017. Disponível em: https://becominghuman.ai/forget-silicon-valley-innovation-is-happening-in-china-nowc6cfdbd74bc4. Acesso em: 15 jun. 2020.

CLEMENTE, Alisson Carlos et al. Gerenciamento de iluminação pública. Revista Científica Multidisciplinar Núcleo do Conhecimento, [s.l.], ano 3, ed. 11, v. 5, p. 107-147, nov. 2018.

CLEMENTE, Felippe; SILVA, Evaldo Henrique da. Avaliação da Lei do Bem sob a ótica do Modelo Principal-Agente. In: I SEMINÁRIO DE AVALIAÇÃO DE POLÍTICAS DE CIÊNCIA, TECNOLOGIA E INOVAÇÃO (CT\&I), 2018, Brasília. Anais do I Seminário de Avaliação de Políticas de Ciência, Tecnologia e Inovação (CT\&I). v. 1, p. 1-15. Brasília, DF, 2018.

ELETROBRÁS - CENTRAIS ELÉTRICAS BRASILEIRAS S.A. Procel/Reluz. [2019]. Disponível em: https://eletrobras.com/pt/Paginas/Procel.aspx. Acesso em: 15 maio 2019.

ESPACENET. [Ferramenta de busca de bases de dados-Internet]. [2021]. Disponível em: http:// lp.espacenet.com. Acesso em: 11 maio 2021.

FREIRE, E.; GUIMARÃES, M. J.; JESUS, K. Estudo de Prospecção Tecnológica em Grafenos. In: VII CONGRESSO NACIONAL DE EXCELÊNCIA EM GESTÃO. 2011, Rio de Janeiro. p.1-15. Anais [...]. Rio de Janeiro, 2011. ISSN 1984-9354,

FU, Y.; ZHANG, X. Trajectory of urban sustainability concepts: A 35-year bibliometric analysis.

Cities, Elsevier, v. 60, p. 113-123, 2017.

GUERREIRO, E. S. et al. Análise de documentos de patentes sobre copaíba: uma comparação entre fontes de dados. Cadernos de Prospecção, Salvador, v. 11, n. 1, p. 26-40, jan.-mar., 2018. 
INPI - INSTITUTO NACIONAL DA PROPRIEDADE INDUSTRIAL. Guia Simplificado para

Buscas em Bases Gratuitas. [2020]. Disponível em: https://www.gov.br/inpi/pt-br/assuntos/ arquivos-cepit/Mdulo3Base Espacenetrevisado09112020.pdf. Acesso em: 12 dez. 2020.

INPI - INSTITUTO NACIONAL DA PROPRIEDADE INDUSTRIAL. Guia Básico de Patentes.

[2021]. Disponível em: http://www.gov.br/inpi/pt-br/servicos/patentes/guiabasico. Acesso em: 18 mar. 2021.

OLIVEIRA, André Henrique et al. Aplicações de Automação em IoT - Internet of Things. Revista Científica da FAEX, [s.l.], 2016.

ORBIT INTELIGENCE. [Ferramenta de busca de bases de dados-Internet]. (OQuestel. 2021. Disponível em: www.orbit.com. Acesso em: 11 maio 2021.

PELLICER, S. et al. A global perspective of smart cities: A survey. In: PELLICER, S. et al. 2013

Seventh International Conference on Innovative Mobile and Internet Services in Ubiquitous Computing. [S.I.]: IEEE, 2013. p. 439-444.

PMB - PREFEITURA MUNICIPAL DE BARREIRAS. 2021. Disponível em: https://barreiras.ba.gov.br/ prefeitura-de-barreiras-inicia-primeira-etapa-da-modernizacao-da-iluminacao-publica-na-br-242-eavenidas-marginais/. Acesso em: 27 maio 2021.

VIEIRA, M. H.; PENNA, T. H.; Estudo comparativo entre a trajetória econômica da Corea do Sul e do Brasil, à luz das políticas de inovação. Revista Forense, [s.l.], v. 431, ago. 2020.

WIPO - WORLD INTELLECTUAL PROPERTY ORGANIZATION. International Patent

Classification (IPC). [2021]. Disponível em: http://www.wipo.int/classifications/ipc/en/. Acesso em: 17 fev. 2021.

\section{Sobre os Autores}

\section{Carlos Barros Rodrigues}

E-mail: cbarrosr03@outlook.com ORCID: http://orcid.org/0000-0001-5284-7164

Graduado em Engenharia Elétrica pela Universidade Federal de Uberlândia em 1984.

Endereço profissional: Universidade Federal do Oeste da Bahia, Reitoria, Rua Professor José Seabra de Lemos, lado par, Recanto dos Pássaros, Barreiras, BA. CEP: 47808-021.

\section{Gabriela Silva Cerqueira}

E-mail: gabriela.cerqueira@ufob.edu.br ORCID: http://orcid.org/0000-0002-3610-4544

Doutora em Química pela Universidade Federal da Bahia em 2017.

Endereço profissional: Universidade Federal do Oeste da Bahia, Reitoria, Rua Professor José Seabra de Lemos, lado par, Recanto dos Pássaros, Barreiras, BA. CEP: 47808-021. 


\section{Cristine Elizabeth Alvarenga Carneiro}

E-mail: cristine.carneiro@ufob.edu.br

ORCID: https://orcid.org/0000-0002-0782-3523

Doutora em Agronomia pela Universidade Estadual de Londrina em 2008 e doutora em Química, na área de Físico-química, em 2012.

Endereço profissional: Universidade Federal do Oeste da Bahia, Reitoria, Rua Professor José Seabra de Lemos, lado par, Recanto dos Pássaros, Barreiras, BA. CEP: 47808-021. 